\title{
Editorial: Publicar en tiempos de pandemia
}

\section{Susana Graciela Pérez Barrera ${ }^{1}$}

Publicar en tiempos de pandemia ha sido una dificultad.

Por un lado, los autores han tenido sus tiempos para la producción bibliográfica reducidos por el aumento de las exigencias que nos ha traído la situación sanitaria provocada por el virus del COVID 19. Aprender y enseñar a trabajar a distancia, a utilizar herramientas tecnológicas que antes no usábamos con tanta frecuencia, crear nuevas alternativas para investigar con muchísimas restricciones para el trabajo de campo y, al mismo tiempo, estimular a nuestros estudiantes a no abandonar sus metas y sus sueños ha representado un gran desafío.

Por otro lado, como editores, mantener estándares de calidad y frecuencia en nuestras publicaciones exige un trabajo de alta dedicación y requerimientos que todavía son muy difíciles de implementar en nuestro país, donde la investigación, particularmente en el área de la Educación, recién comienza a solidificar sus primeros pasos.

El reto de cumplir las acertadas exigencias éticas y democráticas de la Ciencia Abierta tiene un impacto multiplicado para los autores y los editores por la gran demanda de producción científica y la creciente internacionalización, que atrae el reducidísimo número de investigadores senior en Uruguay.

Las revistas de la Facultad de Ciencias de la Educación se están adaptando para cumplir esas exigencias. Todas ellas ya están publicadas en la plataforma OJS (Open Journal System) y ajustándose a los criterios de los principales indexadores.

Particularmente, la Revista Sudamericana de Educación, Universidad y Sociedad (RSEUS) ya ha cumplido los criterios necesarios para la indexación en Latindex Catálogo 2.0, lo que nos ha exigido mucho esfuerzo y cuidado y nos deja muy orgullosos, porque se trata de un reconocimiento importante.

Todos los artículos publicados han sido aprobados por sistema de arbitraje doble ciego de árbitros nacionales e internacionales, cuentan con el Digital Object Identification (DOI) correspondiente y adhieren a la licencia CC-BY 4.0 (Creative Commons Atribución Internacional), que permite que el artículo se comparta y distribuya abiertamente. Además, la revista está afiliada a la Asociación Uruguaya de Revistas Académicas (AURA).

\footnotetext{
1 Doctora en Educación (Pontifícia Universidade Católica do Rio Grande do Sul), Responsable por la Unidad de Investigación, Facultad de Ciencias de la Educación, Universidad de la Empresa, Montevideo, Uruguay. sperezbarera@ude.edu.uy, ORCID 0000-0003-1449-469X
} 
Acorde a esas directrices, los artículos de esta edición comparten visiones diferentes sobre temas muy importantes.

Desde la Facultad de Psicología de la Universidad Nacional de Córdoba, en Argentina, Paula Gabriela Irueste, María Barotto, Sofía Samanón y Melisa Belén Taormina nos comparten el estudio realizado en el año 2019 que buscó conocer el uso de tecnologías en niños y niñas de entre 4 y 12 años de edad, respecto a las pautas transaccionales y las estrategias de socialización implementadas por las familias en el artículo titulado "Uso de tecnologías en las infancias: pautas transaccionales y estrategias de socialización familiares".

El artículo de Edla Maria Gonçalves de Alencar Trigueiro, titulado "A utilização das TICS nas escolas públicas do Brasil: uma revisão bibliográfica do uso no planejamento educacional brasileiro" tuvo como objetivo analizar la utilización de las TICs en las escuelas públicas brasileiras, por medio de una revisión teórica que fundamenta el uso de estas herramientas en aula, para proporcionar una planificación más adecuada para el futuro.

En su ensayo "El Pensamiento Computacional, Educación STEM y la Educación Informática: Cuestiones Pendientes", Manuela Cabezas examina el auge de la frase Pensamiento Computacional (PC) en el campo educativo, desde la perspectiva de las trasformaciones producidas por la computación en los últimos 20 años y su impacto en la educación y busca problematizar el enfoque didáctico del PC desde la perspectiva de la Educación Informática como base para el modelo didáctico de las ciencias computacionales.

Paula Mitsuyo Yamasaki Sakaguti presenta sus reflexiones sobre la relación entre creatividad y resiliencia en la familia superdotada, investigación que realizó con 15 estudiantes que frecuentan las "salas de recursos do Atendimento Educacional Especializado" en la Red Municipal de Enseñanza Curitiba, Paraná, Brasil y sus respectivas familias en el artículo que lleva como título "Altas Habilidades/Superdotação e família: resiliência e criatividade”.

En la próxima edición, esperamos contar con la colaboración de nuevos investigadores, ya que la celeridad permitida por la publicación continua, facilita la divulgación y discusión de estudios de calidad. 